\title{
LCA of energetic biomass utilization: actual projects and new developments-April 23, 2012, Berne, Switzerland
}

\author{
Mireille Faist Emmenegger • Matthias Stucki • \\ Sandra Hermle
}

Received: 10 July 2012 / Accepted: 17 July 2012 /Published online: 11 August 2012

(C) Springer-Verlag 2012

\begin{abstract}
Introduction In the last years, the use of biomass for energy purposes has been seen as a promising option to reduce the use of nonrenewable energy sources and the emissions of fossil carbon. However, LCA studies have shown that the energetic use of biomass also causes impacts on climate change and, furthermore, that different environmental issues arise, such as land use and agricultural emissions. While biomass is renewable, it is not an unlimited resource. Its use, to whatever purpose, must therefore be well studied to promote the most efficient option with the least environmental impacts. The 47th LCA Discussion Forum gathered several national and international speakers who provided a broad and qualified view on the topic.

Summary of the topics presented in DF 47 Several aspects of energetic biomass use from a range of projects financed by the Swiss Federal Office of Energy (SFOE) were presented in this Discussion Forum. The first session focused on important aspects of the agricultural biogas production like the use of high energy crops or catch crops as well as the influence of plant size on the environmental performance of biogas. In the second session, other possibilities of biomass treatment like direct combustion, composting, and incineration with municipal waste were presented. Topic
\end{abstract}

M. Faist Emmenegger $(\bowtie)$

Empa, Überlandstr. 129,

8600 Dübendorf, Switzerland

e-mail: mireille.faist@empa.ch

M. Stucki

ESU-Services Ltd.,

Kanzleistrasse 4,

8610 Uster, Switzerland

S. Hermle

Swiss Federal Office of Energy (SFOE), Energy Research,

Biomass and Combustion,

3003 Berne, Switzerland of the first afternoon session was the update and harmonization of biomass inventories and the resulting new assessment of biofuels. The short presentations investigated some further aspects of the LCA of bioenergy like the assessment of spatial variation of greenhouse gas (GHG) emissions from bioenergy production in a country, the importance of indirect land use change emissions on the overall results, the assessment of alternative technologies to direct spreading of digestate or the updates of the car operation datasets in ecoinvent.

Conclusions One main outcome of this Discussion Forum is that bioenergy is not environmentally friendly per se. In many cases, energetic use of biomass allows a reduction of GHG and fossil energy use. However, there is often a tradeoff with other environmental impacts linked to agricultural production like eutrophication or ecotoxicity. Methodological challenges still exist, like the assessment of direct and indirect land use change emissions and their attribution to the bioenergy production, or the influence of heavy metal flows on the bioenergy assessment. Another challenge is the implementation of a life cycle approach in certification or legislation schemes, as shown by the example of the Renewable Energy Directive of the European Union.

Keywords Bioenergy $\cdot$ Biofuels $\cdot$ Biomass $\cdot$ LCA

\section{Introduction}

In the last years, the use of biomass for energy purposes, such as electricity, heat, and transport services, has been seen as a promising option to reduce the use of nonrenewable energy sources and the emissions of fossil carbon. However, life cycle assessment (LCA) studies have shown that the energetic use of biomass also causes impacts on climate change and, furthermore, that different environmental issues arise, such as land use and agricultural emissions. While biomass is renewable, it is not an unlimited resource. 
Its use, to whatever purpose, must therefore be well studied to promote the most efficient option with the least environmental impacts.

Consequently, there is a need for up-to-date life cycle inventories of biomass and its energetic use to provide such studies with best available data. This was the focus of a range of projects financed by the Swiss Federal Office of Energy (SFOE), which were presented in this Discussion Forum. The inventories developed in those projects will be published to a great extent in July 2012 in the new version of ecoinvent ${ }^{1}$.

In the 47th Discussion Forum, current developments of LCA studies in the field of energy crops, biogas production, biomass combustion, and biofuels were presented. The 47th Discussion Forum also offered the opportunity for short presentations on the topic.

\section{Agricultural biogas production}

The first session of the day was focused on the assessment of agricultural biogas production.

Matthias Stucki (ESU-services, Uster) presented an LCA of biogas from different purchased substrates and energy crops (Stucki et al. 2012). ${ }^{2}$ The substrates studied were sugar beet, fodder beet, beet residues, maize silage, molasses, and glycerin. The inventories of biogas production were based on literature data and on results from a survey of the ENERS company. For the purification step, the study considered a mix of $56 \%$ pressure swing adsorption technology, $26 \%$ glycol washing technology, and $18 \%$ amino washing technology, which are the purification technologies applied in Switzerland. The results show that the environmental impacts of biogas from purchased substrates are in the same range than those from liquid biofuels. The methane leakage rate of the purification technology can make a significant contribution to greenhouse gas emissions in the life cycle. Furthermore, electricity from biogas produced from energy crops is not recommended. Main conclusion from this study is that the current trend towards using high energy substrates made from agricultural crops leads to higher environmental impacts and a worse environmental performance of biogas.

Frank Hayer (FOEN, Bern/Agroscope ART, ReckenholzZurich) investigated the question if catch crops are sustainable for biogas production (Hayer et al. 2011). Catch crops present no direct competition to nutrition and could be used for energy purposes while keeping their ecological function of nitrate

\footnotetext{
$\overline{{ }^{1} \text { www.ecoinvent.org }}$

${ }^{2}$ The inventories of this project can be downloaded at www. lc-inventories.ch
}

capture. However, they are partly used for animal feed and therefore indirectly compete with nutrition. The aim of the study was to develop recommendations for catch crop cultivation and biogas production as well as life cycle inventories (LCI) for the ecoinvent database. The study presented an LCA of the most common cultivated catch crops in different variants (mustard, phacelia, sunflower, oat-vetches mixture (SM101), grass-clover mixture (SM106), grass-clover mixtures (SM 200, SM 210), Italian Ryegrass) under Swiss conditions. The current electricity mix in Switzerland is mainly based on hydro- and nuclear energy resulting in low impacts per kilowatt hour. Due to this fact, electricity produced with biomass from all analyzed catch crop variants shows a higher global warming potential (GWP); also acidification, eutrophication, human toxicity, and, in most cases, terrestrial toxicity impacts per kilowatt hour are higher but on the other side advantages regarding nonrenewable energy use and aquatic ecotoxicity exist. The conclusions are affected by the current electricity mix, the high emissions from biogas production and green manure credit for catch crops. If catch crops should replace European (UCTE) electricity mix imports, an important question to consider is the target, which might be (1) a GWP per kilowatt hour as low as possible or (2) a reduction potential per hectare as high as possible. Therefore, the choice of catch crop variants depends on the target: the first target could be fulfilled with extensive cultivation which has the advantage of low additional environmental impacts compared to green manure, however with low yield and reduction potential. Intensive cultivation is preferable for the second goal of high reduction potential, as these catch crops have a high yield and also a high reduction potential; the drawbacks however are higher impacts per hectare and also per kilowatt hour. In Switzerland, catch crops are currently used mostly as animal feeds. Therefore, there is only a small bioenergy potential for this biomass type without competing with its current use.

Martina Alig (Agroscope ART Reckenholz-Zurich) presented a study on the effects of plant size, i.e., of centralized vs. decentralized production on the LCA results of agricultural biogas production (Dauriat et al. 2011). The study assessed agricultural biogas production as a function of output level (size of production facility), based on real biogas production facilities in Switzerland, which use for production besides the main substrate also waste and nonwaste cosubstrates. Main substrate in this study was manure (liquid and solid); the waste cosubstrates investigated here were residues from the industry and biowaste from communities, whereas glycerine was considered as nonwaste because of its positive economic value. The aims were the identification of the main determinants of the environmental performance of agricultural biogas production calculated with the Swiss Ecological Scarcity Method 2006 (UBP) as 
well as the elaboration of practical recommendations addressed to biogas producers, investors, and political actors regarding the size of agricultural biogas production. Furthermore, the ecoinvent inventories regarding agricultural biogas production (including cogeneration) were updated in order to be integrated in ecoinvent version 3. One main result is that the use of non-waste substrates significantly augments energy demand and overall environmental impacts (in UBP) of biogas production, but can reduce global warming potential impacts. If only waste substrates are used, transport distances (for substrates and digestates) are the main driver for energy demand, whereas storage of digestates dominates the results for GWP and UBP. Furthermore, the environmental impacts are smaller the more cosubstrates are used. Under the assumption of the same proportion of co-substrates for all plants, an augmentation of the plant size compensates the augmentation of transport distances with regard to GWP and overall environmental impact in UBP, but not to energy demand. On farm level, the installation of a biogas plant can significantly reduce the nonrenewable energy demand and - to a smaller extentalso GWP. Alig concludes that the optimal size of a biogas plant is the one which allows optimizing the share of cosubstrates in a radius of $50 \mathrm{~km}$ around the installation while avoiding nonwaste substrates.

\section{Biomass treatment}

The second section of the morning was focused on biomass treatment in different pathways like direct combustion or compost.

René Itten (ESU-services, Uster) presented an LCA on the direct combustion of biomass (Itten et al. 2011). ${ }^{3}$ The main goal of the study was to establish LCIs for the direct combustion of biomass substrates. A second goal was to quantify the environmental impacts of direct combustion and to compare biomass substrates to wooden and fossil fuels. The third goal was to assess the influence of the different substrates and combustion technologies on the emissions and therefore on the overall impacts. The substrates selected for the study were olive pomace, coffee grounds, poultry litter, horse dung, and pig slurry. Data availability determined the choice of the substrates. The measured data came from pilot plants or experiments on lab scale with no flue gas treatment. For the disposal of ashes, the same shares were used as for wood combustion in ecoinvent, which are $25 \%$ percent in sanitary landfill, $50 \%$ in municipal solid waste incineration (MSWI), and $25 \%$ in land farming (which means spread on agricultural land). According

\footnotetext{
${ }^{3}$ The inventories of this project can be downloaded at www. lc-inventories.ch
}

to the results of this study, biomass substrates cause higher environmental impacts compared to wood and fossil fuels when assessed with the Swiss Ecological Scarcity Method 2006 (UBP). However, they cause lower greenhouse gas (GHG) emissions compared to fossil fuels. Therefore, there is a trade-off between GWP and overall environmental impacts measured with UBP 2006. The particle emissions cause the highest share of the impacts according to UBP 2006. There is however a high uncertainty because of lacking data regarding particle size distribution during the combustion of biomass substrates. Some of the biomass substrates cause higher heavy metal emissions than wooden fuels but for most of the substrates, the heavy metal emissions are equal or lower compared to wooden fuels. No recommendation can be made regarding the furnace type, as the data comes mainly from pilot plant without flue gas treatment. This leaves a high potential to reduce particles emissions with basic flue gas treatment.

The audience pointed out that disposing the ashes in MSWI does not seem realistic; $50 \%$ share in MSWI is therefore too high. Furthermore, furnaces should meet the goal of the legislation with regard to air emissions, which was not considered in this study.

Konrad Schleiss (Umweko GmbH, Grenchen) and Mischa Zschokke (Carbotech, Basel) presented a project on the LCA of biowaste treatment (Dinkel et al. 2012). The goals of their study were to assess the environmentally best treatment of biowaste, the relevant emissions in the processes, and finally how the results are influenced by the properties and components of the biowaste. To this end, a workshop had been organized to revise and update the ecoinvent data. Furthermore, one focus of the study was the value of organic matter in LCA to assess the benefits and impacts of the different products and co-products in biomass treatment. They also investigated the issue of heavy metal emissions in this context. One main result of the workshop was that the methane emissions of biological treatment methods were too high in the previous ecoinvent versions. The investigation of the value of organic matter by Swiss farmers and its integration in the LCA of biomass treatment showed that accounting for organic matter in compost and digestate can influence the results significantly. Furthermore, heavy metal emissions into soil have a great impact on LCIA results and should be investigated in more detail. Key issue in this context is that current inventories account for heavy metal input as if it was newly introduced to the system; however, compost, e.g., contains some topsoil and plant material going to compost contains heavy metal previously assimilated from soil by crops. Considering all the new findings, the authors of the study identified the best pathways for the biomass: polluted biomass should be treated in municipal solid waste incinerators; wet, easy-degradable, and biomass with high fat content in anaerobic digestion, dry and woody 
in incineration whereas mixed soil with lignified plant material should be composted.

\section{Biomass and biofuels}

Focus of the first session in the afternoon were new developments and new data in the assessment of liquid biofuels, which were investigated in projects that aimed on one side at updating and developing inventories on cultivation of feedstock and their processing to biofuels and on the other side at updating and extending the assessment of biofuels (Faist Emmenegger et al. 2012).

Thomas Nemecek (Agroscope ART Reckenholz-Zurich) focused in his talk on the biomass cultivation step. The aim of this part of the project was the update, harmonization, and extension of the datasets in the context of bioenergy. The study integrates new emission models and factors for nitrous oxide, ammonia, and nitrate, new methods and better data on land use change (LUC), as well as emerging sources of biomass like jatropha, miscanthus, and salix. IPCC (2006) provides new emission factors for nitrous oxide which were included in the study. For ammonia and nitrate, a harmonization of the calculation methods was implemented for all ecoinvent biomass datasets. The resulting updated $\mathrm{N}$ emissions present on average a slight reduction for ammonia. For nitrate, increases and decreases occur, with, on average, a slight increase. For nitrous oxide, a reduction by about one fourth can be observed compared to the older models. For land use change, a method based also on IPCC (2006) was developed and applied consistently on all biomass datasets. The updated LUC inventories show that emissions from LUC are highly relevant; however, the attribution of direct LUC is charged with high uncertainties regarding to the time period or the causality. The new LUC inventories are parameterized, which allows a fast adaptation to site-specific conditions. On the whole, the new biomass inventories differ in their GHG emissions results, so that a new evaluation of biofuels is necessary.

Mireille Faist Emmenegger (Empa, Dübendorf) presented the second part of the study which assessed biofuels based on the inventories presented by T. Nemecek. The study integrates the new modeling of $\mathrm{N}$-emissions and of GHG emissions from land use change, new inventories for crop cultivation, conversion technologies, and fossil reference as well as new assessment methods. Furthermore, inventory data for the operation of cars were also updated. The results of the LCA on a midpoint level show that biofuels allow the reduction of fossil fuel use and, as long as no LUC emissions occur, also climate change impacts. If one includes emissions from indirect land use changes (iLUC), most land-based biofuels have even higher GHG emissions than fossil fuels. In addition, biofuels have higher impacts than fossil fuels also for many other indicators, except if the process uses biomass wastes as a feedstock. Replacing fossil fuels with biofuels therefore presents a risk of shifting impacts and creating new environmental problems. The study confirms the high diversity in the impact patterns of biofuel pathways, even when made from the same feedstock and therefore underpins the necessity of assessing biofuel projects with specific data. Where biofuel feedstock is grown on agricultural land, measures preventing iLUC emissions and other indirect effects must be taken. The potential for biofuels with no LUC and no iLUC is limited.

\section{Short presentations}

Simon Gmünder (Empa, Dübendorf) presented a sustainability assessment of biofuels value chains from sugar cane and oil palm in Colombia. A special focus of the study was a spatial GHG map showing the potential GHG impacts of biofuel expansion including land use change effects. The results indicate that spatial variation is highly diverse, but that there are as well spots for substantial GHG savings as also "no-go-areas" where GHG emission could exceed those of fossil fuels. He concluded that a spatial LCA approach is suitable for planning of future land use, while the applicability strongly depends on available data and is a first step of regionalization.

David Tonini (Technical University of Denmark, Copenhagen) presented an LCA of bioenergy production from energy crops and enzymatically pretreated municipal solid waste (MSW). The results showed negligible GHG savings when iLUC is accounted for. His conclusions were that willow and miscanthus are the best energy crops for Danish conditions, with co-firing as a preferable technology. Anaerobic digestion should be co-digestion with manure to increase savings; however, there are still no GHG savings when iLUC is included. The focus should be put on residual domestically available biomass (manure, MSW, straw, grass, wood residue, etc.) rather than on energy crops.

Ian Vásquez-Rowe's (CRP Henri Tudor, Luxembourg) topic was the environmental assessment of the technologies of pilot processes and regions in the context of the promotion of energy from biomass in North West Europe to achieve the EU 2020 energy objectives. The undergoing analysis investigates the possibility of nutrient recovery from manure and digestate in Flanders. Indeed, an increase in biogas production will increase the quantity of digestates and cause a nutrient surplus in Flanders. There is a need to identify and assess alternative technologies to spread the digestate. 
Future topics will be the combustion of greenery cuttings from parks and other communal areas (Stoke-on-Trent), dry anaerobic digestion, biogas cleaning, upgrading and injection into the grid (Utrecht), and the assessment of lowimpact crops (short rotation coppices/cover crops).

Andrew Simons (PSI, Villigen) focused in his talk on the new modeling of operation emissions from passenger cars. The goals of his study were the updates, corrections, and expansion of the ecoinvent v2.2 inventories, as well as the determination of accurate reference emissions profiles for technology comparisons and the supplying of methodologically more correct and transparent inventories to ecoinvent v3. A main change in the new operation inventories is the differentiation between exhaust and non-exhaust emissions; furthermore, the emissions profiles were enlarged. The determination of biofuel combustion emissions is based on the improved fossil references. Ecoinvent v3 will therefore supply LCIs for a broad range of conventional fossil fuelled passenger car types.

\section{Outlook}

The last session in the afternoon was dedicated to broaden the scope of the topic.

Bernhard Steubing (Empa, Dübendorf) investigated the environmentally optimal uses of different biomass feed stocks, which can be heating, electricity generation, or transportation (Steubing 2011; Steubing et al. 2012). To this aim, he first determined the sustainably available biomass in Switzerland, which amounts to around $7 \%$ of the Swiss primary energy demand. The LCA assessing all possible conversion routes has the biomass as functional unit and uses as optimization criteria different indicators on a midpoint or endpoint level. The net benefit is defined as the total environmental impacts of the alternatives minus the environmental impacts of the existing technologies. The results were calculated for a Swiss and an EU scenario and show that the environmentally best use of woody biomass (forest and landscape wood, industrial wood residues and waste wood) is heating and combined heat and power, while the use for transportation and biomethanecombined cycle is less beneficial. Nonwoody biomass (manure, food industry waste, biowaste, and sewage sludge) is best for heating, but difference between uses is less pronounced. All uses seem acceptable in Switzerland. However, in the EU, biomass should be mainly used for electricity, and in the future for biofuels. The key factors for high environmental benefits are high biomass conversion efficiencies and the substitution of fossil energy from coal, fuel oil, and other high impact energy carriers. These recommendations may change in the future due to new technologies, changes in supply or in demand of energy services.
Susanne Köppen (IFEU, Heidelberg) broadened the scope to bioenergy in Europe focusing on the EU Renewable Energy Directive (RED) and its implementation. One important mandatory criterion in the RED for the LCA context is that greenhouse gas emission saving of biofuels compared to the fossil reference shall be at least $35 \%$ (50\% after 2017). The Annex V in the RED gives default values (overall and disaggregated) and methodological rules for own calculations of "actual values". Economic operators may use default values, actual values calculated according to Annex V, or the sum of actual value and disaggregated default values. With the increase of GHG saving thresholds, the use of actual values will become more important. Because the RED does not list the conversion factors needed for the calculations like the GHG intensity of fertilizer production, e.g., results of the same pathway might be very different due to diverse conversion factors. The BioGrace project aimed at enhancing transparency and harmonizing the calculations performed in EU-27. ${ }^{4}$ It provides an excel-based GHG calculator based on the RED rules and providing the same conversion factors as those used in the default values. The BioGrace calculator is likely to be recognized by the European Commission and can be used as add-on in all recognized certification systems that do not provide own calculators. In the next steps, the calculator will be constantly updated with regard to default values and methodologies, like the coming methodology on indirect land use change and on the calculation of nitrous oxide field emissions.

\section{Conclusions}

One main outcome of this Discussion Forum is that bioenergy is not environmentally friendly per se. In many cases, energetic use of biomass allows a reduction of GHG and fossil energy use. However, there is often a tradeoff with other environmental impacts linked to agricultural production like eutrophication, e.g., the case studies also showed the high diversity of the results depending on the feedstocks and on the single pathways. Therefore, a case-by-case assessment of bioenergy production pathways is necessary. The use of biowaste for energy tends to be beneficial in most of the cases, whereas the use of land-based energy crops is not favorable from an environmental point of view. New methodological developments like the new emission factors for nitrous oxide did not change these main outcomes of bioenergy assessment. Recent technological progresses, e.g., those leading to a reduction of methane losses in the biogas production, show that there is still potential for improvements in the biofuel production chain with regard to environmental impacts. However, if iLUC is included in LCA studies, the environmental impacts of most biofuels from landbased energy crops exceed the impacts of fossil fuels by far.

\footnotetext{
$\overline{{ }^{4} \text { http://www.biograce.net/ }}$
} 
Methodological challenges still exist, like the assessment of direct and indirect land use change emissions and their attribution to the bioenergy production, or the influence of heavy metal flows on the bioenergy assessment. Another challenge is the implementation of LCA in certification or legislation schemes. The example of the RED shows that legislation based on LCA requires very detailed guidelines to allow comparability of the results. Further, a promising option to assess and plan bioenergy production is the linking of LCA with spatial information.

Acknowledgments We thank the speakers for their interesting contributions to this Discussion Forum. We are deeply grateful for the support from the Swiss Federal Office of Energy (SFOE) for the financing of different case studies and supporting the organization of this Discussion Forum. We thank Karin Flury for her contribution to this paper.

\section{References}

Dauriat A, Gaillard G, Alig M, Scharfy D, Membrez Y, Bachmann N, Steiner R, Charles R, Maltas A, Sinaj S (2011) Analyse de cycle de vie de la production centralisée et décentralisée de biogaz en exploitations agricoles-Rapport final. Auftragnehmer: ENERS Energy Concept. vol Publikation 290493. Bundesamt für Energie BfE, Berne, Switzerland

Dinkel F, Schleiss K, Zschokke M (2012) Ökobilanzen zur Biomasseverwertung. Autragnehmer: Carbotech AG. Publikation 290577. Bundesamt für Energie BFE, Berne, Switzerland

Faist Emmenegger M, Gmünder S, Reinhard J, Zah R, Nemecek T, Schnetzer J, Bauer C, Simons A, Doka G (2012) Harmonisation and extension of the bioenergy inventories and assessment. Draft report. Bundesamt für Energie BFE, Berne, Switzerland

Hayer F, Scharfy D, Gaillard G, Anspach V, Albisser Vögeli G (2011) Ökobilanzierung des Anbaues von Zwischenkulturen zur Biogasproduktion - Schlussbericht. Auftragnehmer: Ernst Basler+ Partner AG, Forschungsanstalt Agroscope Reckenholz-Tänikon ART, Arbeitsgemeinschaft zur Förderung des Futterbaues (AGFF), Schweizerischer Bauernverband. Publikation 290518. Bundesamt für Energie BFE, Berne, Switzerland

IPCC (2006) Guidelines for national greenhouse gas inventories. Volume 4: Agriculture, forestry and other land use. Kanagawa, Japan

Itten R, Stucki M, Jungbluth N (2011) Life Cycle Assessment of Burning Different Solid Biomass Substrates - Schlussbericht. Auftragnehmer: ESU-services Ltd., Publikation 290422. Bundesamt für Energie BFE, Bern

Steubing B (2011) Analysis of the availability of bioenergy and assessment of its optimal use from an environmental perspective. Ph.D. thesis, ETHZ, Zurich, Switzerland

Steubing B, Zah R, Ludwig C (2012) Heat, electricity, or transportation? the optimal use of residual and waste biomass in Europe from an environmental perspective. Environ Sci Technol 46 (1):164-171

Stucki M, Jungbluth N, Leuenberger M (2012) Life Cycle Assessment of Biogas Production from Different Substrates - Schlussbericht. Auftragnehmer: ESU-Services Ltd., Publikation 290514. Bundesamt für Energie BFE, Berne, Switzerland

All presentations of the Discussion Forum are available for download at http://www.lcaforum.ch/Downloads/DF47/tabid/94/Default.aspx.

The reports of the cited projects are available for download at http:// www.bfe.admin.ch/forschungbiomasse/02390/02720/03175/ index.html?lang=de. 